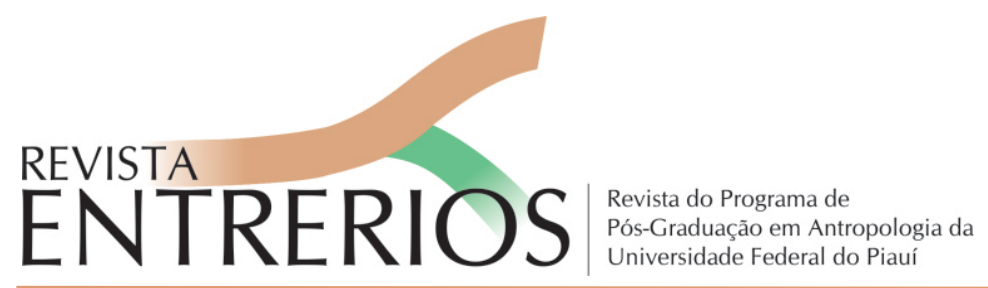

\title{
Antropologia e educação quilombola: etnicidade e mediação
}

\author{
Dra. Neusa Maria Mendes de Gusmão1 \\ Antropóloga e Profa. Titular
}

neusagusmao@uol.com.br

\begin{abstract}
Resumo: O presente texto pretende fazer uma leitura da educação quilombola, tal como se apresenta em pesquisas contemporâneas com a finalidade de refletir os processos educativos inerentes à proposta oficial da educação quilombola e a forma assumida por ela em diferentes contextos. Busca-se assim, pensar quais as categorias que efetivamente se constroem em conjunto com a politica e com a cultura de diferentes grupos, posto que, mesmo sendo quilombolas, são eles diversos e constroem a vida em contextos também diversos. $O$ debate considera o conjunto das relações vividas por duas comunidades quilombolas, uma no estado de São Paulo e ou tra no estado do Rio de Janeiro, a título de exemplos da luta por educação específica e diferenciada, ou seja, a luta por uma educação quilombola. Pretende-se considerar em tais contextos, a questão da etnicidade e da mediação para evidenciar as experiências vividas que se revelam como aprendizagens em contextos de mudanças sociais e políticas que se fazem necessárias no campo da luta pela terra e por direitos específicos.
\end{abstract}

Palavras-chaves: Antropologia; etnicidade; mediação; educação quilombola.

\begin{abstract}
The present text intends to make an analysis of quilombola education, as it is presented in contemporary research with the purpose of reflecting the educational processes inherent to the official proposal of quilombola education and the form taken by it in different contexts. Thus, we seek to think about which categories are effectively built together with the politics and culture of different groups, since, even though they are quilombolas, they are a diverse group and life in different contexts. The debate considers the set of relationships experienced by two quilombola communities, one in the state of São Paulo and the other in the state of Rio de Janeiro, as examples of the struggle for specific and differentiated education, that is, the struggle for quilombola education. It is intended to consider in such contexts the issue of ethnicity and mediation in order to highlight the life experiences that are revealed as learning in contexts of social and political changes that are necessary in the struggle for land and for specific rights.
\end{abstract}

Keywords: Anthropology; ethnicity; mediation; quilombolaeducation.

1 Antropóloga e professora titular (aposentada) do DECISE - Departamento de Ciências Sociais na Educação e do Programa de Pós-Graduação em Educação - FE/UNICAMP e da Pós-Graduação - Doutorado em Ciências Sociais (Antropologia) do IFCH/UNICAMP.

EntreRios - Revista do PPGANT -UFPI -Teresina • Vol. 3, n. 1 (2020) 


\section{Introdução}

O contexto educativo das populações negras, indígenas e outras marcadas por diferenças de origem, língua, cultura, etc., exige que se pense em processos de etnicidade e de mediação, de modo a discutir categorias e processos constitutivos do tecido social que envolvem a educação dos chamados "outros", numa sociedade hierarquizada e estratificada como a brasileira.

Nesse contexto, cabe como pressuposto, pensar que etnicidade e mediação, além de serem processos inerentes à vida social, são também, categorias próprias do campo científico, cuja natureza é a de fornecer instrumental para decodificar e explicar determinadas realidades contemporâneas ${ }^{2}$. Contudo, as categorias são datadas e determinadas por campos teóricos, eles próprios flexíveis e datados, de modo que teorias e categorias, tanto podem propiciar reflexos no meio social, científico e político, como podem deles serem imanadas.

Como afirmo em outro texto (GUSMÃO, 2020a) ainda inédito, as categorias podem ser compreendidas numa rede de interdependência de sentidos conforme os sujeitos em presença e os interesses colocados em contexto. Nesse movimento, configuram-se novas formas interpretativas e identitárias dos próprios grupos na luta para serem reconhecidos em suas especificidades e na natureza da cultura que os particulariza. Será essa relação dos movimentos quilombolas por educação e as formas de atuação do Estado via políticas públicas específicas, o contexto fundamental de concretização dos processos de etnicidade e mediação.

Como afirma Valle (2015), etnicidade e mediação se fazem como política e cultura na medida em que colocam:

mundos sociais [...] em interação através de agentes e atores variados, cuja heterogeneidade sugere que a negociação de significados e sentidos seria uma questão central para se entender as práticas e processos de mediação que se desenrolam em sua dupla face, seja societária como cultural (p.37).

A partir da contribuição de Valle, este texto pretende fazer uma leitura da educação quilombola, tal como se apresenta em pesquisas contemporâneas com a finalidade de refletir os processos educativos inerentes à proposta oficial da educação quilombola e a forma assumida por ela em diferentes contextos. Busca-se assim, pensar quais as categorias que efetivamente se constroem em conjunto com a política e com a cultura de diferentes grupos, posto que, mesmo sendo quilombolas, são eles diversos e constroem a vida em contextos também diversos.

É importante que se diga, que os contextos a serem apresentados, constituem realidades emergentes após as conquistas da Carta Magna da nação brasileira, de 1988, que garantiu direitos específicos para populações negras, indígenas e tradicionais. A Constituição de 1988 é o marco, no qual, se

expressam mudanças históricas importantes na configuração das relações dessas populações com o Estado brasileiro, nos modelos intelectuais de compreensão da participação das mesmas na sociedade brasileira e nas organizações políticas dessas populações no quadro das instituições nacionais (BEZERRA, 2015, p. 8).

Segundo o autor,

A mobilização dos direitos constitucionais relativos às populações culturalmente distintas está associada a processos complexos que envolvem, frequentemente, as próprias populações reconhecidas como sujeitos destes direitos, os representantes de diferentes órgãos estatais, organizações civis, universitárias, partidárias, religiosas e agências multilaterais. Ao se observar com atenção esses processos [...], constata-se que eles implicam em diferentes práticas de mediação social (BEZERRA, 2015, p.8/9).

2 A ideia de mediação se constituiu no campo dos estudos agrários e se redefiniu nos anos de 1950 e 1960 com base em pesquisas etnográficas, estudos sociológicos e ciência política, conforme Bezerra (2015) e, aqui se apresenta em acordo com Valle (2015), como explicitamos mais à frente.

EntreRios - Revista do PPGANT -UFPI -Teresina • Vol. 3, n. 1 (2020) 
O que aqui se pergunta é: como tais processos ocorrem? O que revelam em termos de etnicidade e mediação? Finalmente, pretende-se demonstrar alguns pontos de interação entre antropologia e educação quilombola, com a finalidade de refletir a respeito da questão da diversidade social e cultural presente em processos educativos escolarizados ou não.

Para tratar as mediações em contextos de educação quilombola é preciso ter em mente as limitações de um artigo e do próprio tema. Assim, opta-se aqui por um recorte no jogo complexo das práticas de mediação, para que seja possível traçar um panorama, mesmo que parcial, dos contextos em que as mediações ocorrem. Para tanto, busca-se evidenciar alguns elementos que se apresentam no conjunto das relações vividas por duas comunidades quilombolas, uma no estado de São Paulo e, outra no estado do Rio de Janeiro, a título de exemplos da luta por educação específica e diferenciada, ou seja, a luta por uma educação quilombola. Pretende-se considerar em tais contextos, a questão da etnicidade e da mediação para evidenciar as experiências vividas que se revelam como aprendizagens em contextos de mudanças sociais e políticas que se fazem necessárias no campo da luta.

A proposta será desenvolvida segundo alguns parâmetros, quais sejam: o modo de incorporação dos dois grupos quilombolas à esfera do Estado; as formas de assimilação e/ou de resistência e luta; o encontro ou desencontro das perspectivas culturais presentes no processo; as condições de emergência de sujeitos mediadores; os elementos presentes no jogo das mediações, entre estes a etnicidade e as formas de organização coletivas, bem como, os resultados efetivos das ações praticadas no interior dos grupos considerados.

\section{Quilombo Brotas: Itatiba/SP ${ }^{3}$}

O Quilombo Brotas, situado no município de Itatiba/SP, é formado por 170 pessoas ${ }^{4}$, parentes e descendentes dos primeiros moradores: Emília, Isaac e sua filha Amélia. Seus descendentes contam que Emília e Isaac, após a alforria, em fins de 1880, compraram as terras onde moram para garantir liberdade e autonomia a todos os que viriam, e isso mobiliza o grupo até os dias atuais, dando sentido à terra comum e à vida entre parentes.

A memória da compra da terra, do trabalho árduo dos ancestrais e da intencionalidade de resistência a uma sociedade desigual e discriminatória foi colocada no cenário de lutas dos quilombolas a partir dos anos 2000, diante das investidas dos setores imobiliários e desenvolvimentistas municipais que ameaçavam a permanência das famílias nas terras.

A organização do grupo em defesa da terra, se dá nos anos de 2000, momento em qual passam a designarem-se como quilombolas. Antes da luta, eram eles, os negros do Sítio das Brotas ou Sítio da Tia Lula. Nessa época, suas terras distavam do meio urbano, situado a pouco menos de uma hora de distância. Eram assim, os negros de um sítio que mediante a luta institucional, jurídica e política iniciada em 2000, transformam sua realidade e passam a se identificar como quilombolas. O resultado dessas lutas será o reconhecimento do grupo como remanescente de quilombo ${ }^{5}$, em 2004 e, de sua gente, oficialmente como quilombolas. Quem se fazia presente nessas lutas? Como o grupo organizou-se diante das ameaças dos grupos de fora por sua terra?

3 OQuilombo de Brotas foi estudado por Marcia Lúcia Anacleto de Souza em dois momentos: no mestrado em 2009 e no doutorado em 2015, ambos sob minha orientação, junto a Pós-Graduação da FE/UNICAMP.

4 Dados de 2013. Parte do que é aqui descrito encontra-se publicado na Revista Contemporânea de Educação (GUSMÃO; SOUZA, 2018), e na dissertação de mestrado de Souza (2009)

5 Reconhecimento com base no Art. 68 do Ato das Disposições Constitucionais Transitórias, da Constituição Federal de 1988, que afirma: "Aos remanescentes das comunidades dos quilombos que estejam ocupando suas terras é reconhecida a propriedade definitiva, devendo o estado emitir-lhes os títulos definitivos". 
O campo político e identitário do grupo na relação com a sociedade envolvente, irá caracterizar o grupo e suas terras como pertencentes a um quilombo urbano. Nesse contexto, e pela própria urbanidade à suas portas, evidencia-se a complexidade das identidades que informa quem se é, enquanto quilombola e negro e, quem é o outro, de fora, que discrimina e exclui. Neste sentido, ser quilombola é viver entre a afirmação e a negação, de acordo com os sujeitos da relação: os que valorizam o Quilombo como lugar de luta e parte da história de resistência e tradição negra; os que negam o território e consideram seus sujeitos como invisíveis, seja pelo avanço imobiliário que não respeita os limites do grupo; seja no caso da escola, que os vê como sujos e repulsivos, pobres e alvo de subjugação.

No processo de luta e no cotidiano das relações internas e externas ao grupo, dois espaços educacionais se revelam: um no cotidiano do grupo, nas brincadeiras das crianças, na vivência com os adultos e suas práticas no interior do quilombo e, outro na escola fora do quilombo. Escola municipal que recebe as crianças quilombolas e, também, crianças da redondeza urbana. Nesse sentido, a escola oficial se faz instituição do sistema educacional vigente, comum a todos e, que se organiza conforme a legislação vigente, a LDB. Portanto, a realidade do quilombo Brotas, ensejou a organização do grupo na luta pela terra, mas não conta ainda com uma educação quilombola regida pela Lei 10.639 e seus derivados legais ${ }^{6}$. Como, portanto, o Quilombo Brotas, expressa essa problemática na luta pela terra e na educação?

As práticas cotidianas locais possibilitam conhecer todos os sujeitos que ali vivem, a sociedade que os circunda e os afeta direta e indiretamente. Nesse sentido, a cultura do grupo é apreendida, significada e reelaborada no cotidiano, por meio de múltiplas relações e em diferentes espaços, permitindo construir o entendimento dos modos como os sujeitos educam e são educados ao pertencimento étnico-racial, nas formas de ocupar os espaços na vivência de um momento histórico específico: a luta pela terra quilombola.

Ao se organizarem em torno do movimento social de luta pela terra, o quilombo de Brotas realiza um processo educativo de caráter mais geral que a educação escolar e que abrange a todos, crianças, jovens, adultos e velhos. Ou seja, como diz Souza (2009), trata-se de uma

educação, que abrange "situações sociais de aprender-ensinar-aprender" (BRANDÃO, 1984, p. 14), em que o saber é transmitido e apreendido "pelos atos de quem sabe-e-faz, para quem não-sabe-e-aprende" (Ibid, p. 18), sem intencionalidade explícita, mas durante o próprio fazer e viver. Assim, estamos falando da educação que ocorre em diferentes espaços sociais, e não na educação escolar (p.115).

Ainda segundo Souza (2009),

no processo organizativo dos movimentos sociais participam vários agentes, como assessorias técnicas, políticas, religiosas, os quais atuam junto aos grupos, possibilitando que eles agreguem informações sobre seus direitos, a forma de garanti-los e o funcionamento dos órgãos responsáveis por executá-los. Nesta organização política, os grupos também identificam os interesses opostos ao movimento, partindo então para a elaboração de estratégias de formulação de demandas e ações (p. 116).

6 Refiro-me a Lei 11645 que alterou a Lei 10 639/2003 incorporando ao ensino da história africana e afro-brasileira, a história e cultura indígena. 
Com isso, pode-se afirmar que agentes mediadores da relação do grupo com o Estado por seus direitos, atuam num contexto político em que ensino e aprendizagem envolvem diferentes sujeitos, dentre os quais, funcionários de órgãos oficias como o Instituto de Terra do Estado de São Paulo - ITESP -, organizações governamentais tais como órgãos públicos municipais, estaduais e federais, outras organizações não governamentais, como a ONG Pró- Cidadania, etc. Assim, o processo vivido implica na dimensão da cultura política do grupo que se organiza mediante agentes internos e externos que modulam o movimento social de luta pela terra.

Nesse contexto em que, não apenas aprendem o que até então não conheciam, mas aprendem, também, com outros processos, formas de interpretar o passado grupal de compra da terra pelos antepassados como garantia de seus direitos e, com os quais buscam compreender o presente da luta e as perspectivas do futuro. É assim, que a memória dos mais antigos, da compra da terra e dos laços de parentesco confirmam o lugar e dizem deles, daquilo que são enquanto negros, parentes e herdeiros de Isaac e Amélia. Criam também, a Associação Cultural Quilombo Brotas, que será a interlocutora legal na elaboração do Relatório Técnico-Científico - RTC, e com as demandas dos órgãos públicos, mas não só. Na medida em que a Associação interage no interior do movimento negro quilombola, passa o mesmo a se relacionar com outras comunidades negras e suas lutas num intenso aprendizado enquanto grupo étnico em busca de reconhecimento como grupos portadores de uma cultura negra e específica.

$\mathrm{Na}$ aprendizagem do que é ser quilombola, não só grupos negros se fazem presente, mas, como diz Souza

a identidade quilombola também se constrói em meio às múltiplas identidades de seus moradores, na relação com outros sujeitos, negros e brancos, que os vêem como negros de um Sítio comprado por ex-escravizados e onde, durante cinqüenta anos, houve também rituais de matriz africana. São identidades construídas em diferentes espaços de relações sociais dos moradores do Quilombo, tais como: o trabalho, a escola, a igreja, os centros de saúde e a prefeitura. Nesses espaços, os Outros têm informado aos moradores do Quilombo quem são, demarcando a diferença entre os grupos. Através dessas relações os moradores do Quilombo também constroem sua identidade, marcada pela discriminação, a ameaça de perda da moradia e a dificuldade no acesso a políticas sociais de melhoria da qualidade de vida (SOUZA, 2009, p. 136).

O racismo e o preconceito existentes na sociedade como um todo, são evidenciados nas diversas relações do grupo negro de Brotas com o espaço urbano e com seu entorno. A título de exemplo de formas discriminatórias e de negação dos negros na teia de relações vividas, está a realidade da escola do Município, onde estudam suas crianças e jovens. Será no espaço formal de ensino do campo educacional que as formas de negação das identidades quilombolas operam negando o pertencimento a uma condição étnica e cultural marcada por especificidade histórica. Assim, se são os processos informais de aprendizagem no cotidiano grupal os responsáveis pela emergência étnica no interior da luta pelo território que envolve agentes internos e externos, diz Souza (2009), qual, então, a atuação da escola diante da diversidade étnica e cultural dos moradores do quilombo?

A autora diz que a afirmação e o reconhecimento da identidade quilombola, em 2004, revelou com intensidade, situações em que as crianças e adolescentes do Quilombo, sofreram discriminação na escola. Antes do reconhecimento como quilombo, de acordo com relatos dos estudantes acontecia que:

Na escola era muito preconceito! Nossa, a turma vivia tirando sarro de nós que agente que morava aqui dentro. Aí era muito xingamento. Xingava a gente de negrinha, falava que a gente morava na senzala, sabe. Falava um monte, falava muito, falava um monte e xingamento mais feio. Que a gente era pano de velório. Falava um monte de coisas (SOUZA, 2009, p.156). 
Nesse sentido, a escola reproduzia os valores e os preconceitos vigentes na sociedade como forma de discriminar e evidenciar a posição dos chamados "outros" na escala social. Situação essa, reflexo das relações de poder numa sociedade monocultural, branca, cristã e capitalista que, segundo Souza (2009), não reconhece a diversidade cultural e opera no sentido de reproduzir a hierarquização social, com "discursos que seguem na contramão da luta das populações quilombolas" (SOUZA, 2009, p.153).

Com o reconhecimento como quilombo e a sua gente como quilombola, organizados na defesa dos moradores, por meio de uma Associação, será esta a intervir nos episódios de discriminação na escola e, que agora, em menor intensidade ainda acontecem. A forma de agir da comunidade do quilombo é o de se fazer presente no espaço escolar contando sua história, falando de sua cultura. É assim, que algumas mudanças ocorrem na relação do grupo com a escola e desta para com o grupo. Como diz uma depoente à Souza, o reconhecimento trouxe prestígio à comunidade e agora, a pressão diminuiu, mas por vezes, de modo negativo, diz-se que as crianças são "quilombada". Contudo, desde o reconhecimento da realidade do grupo como quilombo, a forma de se ver das próprias crianças tem se constituído em um empoderamento aprendido na cotidianidade do grupo, na luta pela terra, por sua cultura e por uma história própria e singular. Desse modo, crianças e jovens afirmam suas identidades e pertencimento ao universo negro e ao quilombo, mesmo quando negadas e discriminadas no ambiente escolar.

Tudo isso reflete as dificuldades das comunidades quilombolas que não possuem a escola dentro de seus territórios, mas, a pergunta que fica desse caso exemplar é: a existência da escola nos moldes da sociedade inclusiva no território quilombola constituiria uma realidade diferente? Uma realidade em que a diversidade social e cultural de cada grupo quilombola seja efetivamente considerada? Que a especificidade da história negra e afro-brasileira se façam presentes nos conteúdos formais a serem ensinados?

O Quilombo do Campinho da Independência, em Paraty, no estado do Rio de Janeiro, conta com uma escola no interior do grupo. Escola que é anterior ao processo de luta pela terra, e que foi resultado da ação do grupo negro em sua localidade, contudo, passou a integrar o sistema educacional público do município de Paraty. O que isso significou e significa na história e trajetória do grupo negro de Campinho que tem a escola nas terras do grupo?

\section{Quilombo Campinho da Independência: Paraty/RJ}

Campinho da Independência faz parte do município de Paraty localizado ao sul do estado do Rio de Janeiro e, já nos anos de 1970, estava organizado internamente em torno da luta pela terra. Uma luta cheia de percalços em função do fato de não disporem de documentação que evidenciassem serem eles, legítimos donos da terra. Diante das dificuldades impostas pelo sistema legal vigente, naquele momento, o grupo e sua gente encontravam-se desprovidos de recursos necessários à luta. Nesse processo, vivenciavam então idas e vindas, em meio as ameaças de pretensos proprietários de sua terra e receios de violências reais e simbólicas, desde a presença de jagunços armados, queima de suas roças, bem como, a presença de pessoas que diziam estarem ali posto que alguém deste ou daquele grupo, fazendeiros conhecidos da região e com terras limítrofes as terras do grupo, eram os donos dessas terras e, eram eles que tinham "permitido" que ali, o povo de Campinho, estivesse.

Tantas ameaças reais ou não, os fragilizava como grupo e os percalços legais estabelecidos desde fora, colocavam o grupo negro de Campinho, diante dos poderes constituídos, dos quais desconheciam sua natureza e princípios baseados em documentação e procedimentos legais baseados na escrita, a qual, em maioria, desconheciam.

7 O Quilombo de Campinho foi estudado por mim no mestrado em 1979 e no doutorado em 1990, este publicado pela Fundação Palmares (GUSMÃO, 1995). 
A história da comunidade, centrada na oralidade e na comunicação dos mais velhos com as gerações mais novas, se fazia em meio a fragmentos de memória que diziam de ali estarem, desde muito tempo.

Um tempo em que, a memória falava de três escravas de uma Casa Grande - Vovó Antonica, sua irmã, Tia Marcelina e Vovó Luiza - três mulheres primas entre si e fundadoras do grupo negro de Campinho, em terras doadas pelos donos de antiga fazenda - "assim de boca, porque naquele tempo, não tinha papel" - e, quando a decadência econômica da região paratyense e os movimentos pró-abolição colocavam terras e escravizados como de pouco valor. A memória dos mais velhos registra que, o que restava, eram mesmo, as terras e eles, já que "aqui sóficou mesmo a gente e Deus, perdidos entre as montanhas"

O que é possível dizer é que, a luta pela terra entre os anos de 1970/1980, atraiu para o grupo a atenção de diferentes agentes externos, tais como a Igreja Católica via pastorais e a organização como CEB - Comunidade Eclesial de Base, a qual o grupo primeiramente se organiza, via Pastoral da Terra. Em concomitância, a liderança interna do grupo se faz agente ativo junto ao Sindicato Rural de Paraty e atua nas lutas do meio rural do município, aprendendo a política e trazendo novos saberes para a organização dos negros de Campinho. Os novos saberes também contam com a troca no campo jurídico com advogados da Instituto de Apoio Jurídico Popular - AJUP - que atuavam nas questões da luta pela terra, e, é assim, que compreendem as dificuldades da luta jurídica a que estavam envolvidos já desde muito, com base na legislação vigente. No processo, agentes partidários locais, também passam a dialogar com o meio rural e, será a partir dos negros de Campinho e de sua liderança que, com a possibilidade do multipartidarismo de1982, o Partido dos Trabalhadores - o PT - se faz presente no contexto político local e regional. A partir dos anos de 1990, a luta se fortalece com a presença do Movimento Negro que traz uma visão mais positiva da condição negra do grupo, que sempre sofreu processos de negação e discriminação por serem negros e, também, camponeses vistos como "caipiras" e pobres.

Portanto, a história grupal foi tecida com a colaboração de diferentes agentes internos e externos ao grupo, suas lideranças e, tudo isso configurou um movimento social intenso e complexo que envolveu diferentes grupos na história da luta pela terra. Serão esses agentes mediadores, os interlocutores para com o grupo e, deles para com o Estado, de modo a subsidiar o reconhecimento do grupo negros de Campinho, como quilombolas e, a sua terra como terra pertencente a um quilombo. Uma terra território, imantada pela história grupal, pela descendência das três mulheres que configuram uma realidade baseada no estreito parentesco e na cor negra de sua gente. O intenso parentesco organiza as relações de convívio, de troca, de direito sobre a terra e do que é produzido. Assim, o que se tem é uma comunidade negra rural, que vive a dupla dimensão de ser camponesa e negra, tendo por central nesse contexto, a terra, compreendida como Terra de Pretos ou seja, um

espaço físico e social marcado por formas de organização próprias, investido de uma história particular e ideologizada, um território. (...) Ao mesmo tempo é terra camponesa, que a sociedade tende a incorporar como mercadoria (GUSMÃO, 1995, p. 16).

Pode-se afirmar então, que no processo de luta pela terra, a memória ancestral dá forma a uma memória identitária; aciona a valorização da condição da negritude e, já nos anos de 1990, os conduz a uma nova etapa da luta pela terra, por meio do Art. 68, das Disposições Transitórias, aprovada pela Constituição de 1988.

Como tenho dito em outros escritos (GUSMÃO, 1995; 2016a) nesse contexto, a partir do dispositivo legal e da própria luta, Campinho da Independência se posiciona diante das pressões sobre suas terras, sua gente, redescobre e ressignifica sua diferença a partir da cor e do parentesco, assumindo suas experiências mais remotas. 
Na luta, reconstrói sua memória de pertença ao lugar e assume a condição negra de sua gente. Assume que sua terra, não é uma terra qualquer, mas uma terra de negros e como tal, um território singular e próprio. Uma terra imantada pela história e memória das três mulheres da origem, das quais, ainda hoje, todos, em alguma medida, descendem.

Dez anos após a Constituição ser promulgada, ou seja, em 1998, Campinho da Independência encontrou um caminho aberto para a conquista de sua terra. As motivações políticas de reeleição de Fernando Henrique Cardoso com vistas ao apoio da população negra brasileira e, concomitante, devido a pressões do Movimento Negro abre-se a possibilidade do reconhecimento de algumas comunidades negras, dentre elas, a Comunidade de Campinho da Independência. Mais uma vez, interesses externos e agentes externos colocam em movimento a intermediação e a mediação desse grupo perante o Estado, que agora acena de modo positivo para suas reivindicações. Não importando os jogos de interesses outros desse momento político, será esse o momento de conquista definitiva das terras pelo povo de Campinho, não mais pela luta inglória via usucapião como no passado, mas pelo direito insurgente representado pelo Art.68 das ADCT.

O Laudo Territorial ${ }^{8}$ realizado entre fins de 1997 e janeiro de 1998, garantiu os trâmites legais, políticos e burocráticos pelos quais Campinho da Independência foi reconhecida como comunidade remanescente de quilombo pelo Decreto Estadual 25.210 (10/03/1999) e publicado pelo Diário Oficial do Estado do Rio de Janeiro em 11 de março do mesmo ano.

É assim que,

\begin{abstract}
Os descendentes das três mulheres, nos dias de hoje [1990], configuram de sete a oito gerações compostas por filhos, netos, bisnetos, trinetos, tetranetos e são todos herdeiros da terra e de tudo que nela existe. O direito se garante por meio de um sistema de parentesco real e simbólico que os une e define o lugar que se ocupa no interior desse grupo negro e rural. Pelas regras do parentesco sabe-se quem se é e qual a sua história. $\mathrm{O}$ ponto focal de vida e existência pessoal e coletiva é a terra, pois é ela que torna compreensível a trama da vida vivida no passado e no presente das relações do grupo entre si e com o lugar (GUSMÃO, 2016a, p. 366).
\end{abstract}

O contexto que aqui se descreve de modo parcial, foi o pano de fundo de muitas outras ações coletivas do grupo negro de Campinho, posto que muito antes do reconhecimento e da posterior titulação das terras, outras tentativas de organização do grupo para se fazer representar na luta pela terra, já tinham acontecido. A organização em torno de uma Comunidade Eclesial de Base, uma CEB e como membro da Comissão Pastoral da Terra, ainda nos anos de 1975 em diante, lança as bases do que será a Associação de Moradores de Campinho, a AMOC. Tal organização precede a organização que obedece aos dispositivos do Art. 68 da ADCT, qual seja uma associação local que responda como pessoa jurídica e coletiva pela terra comum. Assim, a partir da segunda metade dos anos de 1990, a comunidade negra responde por si diante da sociedade inclusiva como Associação dos Moradores do Quilombo do Campinho - a AMOQC. Nesse processo, também cabe ressaltar que nos anos de 1990 o fortalecimento da comunidade em termos da coletividade contou com

o movimento negro de natureza urbana, nos anos de 1990, que ao se voltar para a luta negra no campo, alavancou o processo de constituição da associação local e de formação política dos mais jovens. Ao motivar e arregimentar jovens do universo rural, o movimento negro fortalece as possibilidades de (re)organização dos grupos e localidades de historicidade própria, como o caso de Campinho da Independência (GUSMÃO, 2016a, p.368).

8 Elaborado por mim, a pedido da Fundação Cultural Palmares, quando ainda era incipiente a compreensão em torno de laudos dessa natureza e de sua condição de instrumento jurídico e político na questão de terras dos quilombos.

EntreRios - Revista do PPGANT -UFPI -Teresina •Vol. 3, n. 1 (2020) 
É nesse sentido, que em 1995, os jovens negros de Campinho criam o QCI - Quilombo Contemporâneo de Campinho da Independência, já envoltos pelas determinações do Art.68 e, posteriormente, a Associação de Moradores de Campinho - AMOC - que é anterior a esse momento, se transforma em Associação de Moradores do Quilombo do Campinho - AMOQC, para fins de atendimento das exigências jurídicas e legais posta em andamento pela Constituição. O processo fortalece novas lideranças que irão modelar ações internas e externas, com marcas do movimento negro e que lhes dá visibilidade para além do próprio grupo.

No texto de 2016a, afirmo que Campinho da Independência, desde 2007, integra o Fórum de Comunidades Tradicionais Quilombolas, Indígenas e Caiçaras ${ }^{9}$ que atua em defesa dos interesses e direitos dessas comunidades em busca de sua auto-sustentabilidade. $\mathrm{O}$ novo momento considera, sobretudo, os mais jovens e dentre as muitas atividades de que participam em prol do desenvolvimento local, está agora, a luta comum com outras comunidades negras rurais e a atuação em órgãos estaduais e nacionais de luta negra. Isso só foi possível, dado a visibilidade alcançada pelo reconhecimento como quilombo e pela cooperação política com grupos do movimento negro carioca, partidos políticos e agências civis de desenvolvimento, ONGs, que passaram a atuar no sentido de criar nova realidade. Esse movimento, bem complexo em suas posturas e interesses, conta sempre com processos de intermediação e de mediação, que dinamiza o campo político e as relações entre grupos e com o Estado-nação.

Em razão da conquista da terra de Campinho pelo Art.68 e pelo reconhecimento como quilombo, o grupo negro pode atualmente, concorrer a editais públicos com projetos que visam o bem estar da coletividade, e dentre estes, situa-se a demanda por uma educação quilombola.

Contudo, antes desse tipo de demanda, no passado do grupo, o acesso a escolas do pólo urbano de Paraty ou a escolas rurais eram extremamente difíceis, os mais velhos ensinavam aos mais novos a ler e escrever dentro do ambiente doméstico. Mais tarde, duas salas - pau-a-piqueconstruídas em mutirão pelo povo do Campinho, se fizeram classes de anos iniciais de escolaridade integradas ao sistema municipal de educação. Como escola rural e negra, as dificuldades de se contar com professores oriundos do centro urbano eram significativas, de modo que quase sempre a escola ficava sem professores. Por outro lado, além da pouca vontade de assumir a escola "pois ali só tem negro", quando ocorria de o professor morar com as famílias locais, nem por isso, a discriminação se fazia menor (GUSMÃO, 1995). Fatos esses, que prejudicavam o ensino e a aprendizagem das crianças do lugar como demonstra a fala de uma professora moradora na comunidade nos idos de 1980, ao afirmar que, dado que são negras e pobres, essas crianças tinham poucas condições mentais e, assim, eram incapazes de aprender.

A escola maior e de tijolos, também construída em mutirão pela comunidade e com recursos próprios ainda nos anos de 1980, hoje, é de fácil acesso pela Rodovia BR-101, mas, mesmo assim, persistem as dificuldades em manter professores, embora seja uma escola municipal que recebe, também, crianças de localidades próximas. Atualmente, a escola conta com equipe escolar mais regular, sem, contudo, ter as dificuldades das relações no chão da escola, inteiramente resolvidas. A escola que é vista como um orgulho local, uma conquista do grupo negro, da comunidade, contudo, por ser uma escola inserida na ordem mais geral do sistema educacional, se organiza de modo a perpetuar um ensino de natureza ampla que não atende as especificidades da cultura negra e quilombola a despeito da existência de Leis como a lei $10639 / 2003^{10}$ e outros dispositivos legais em torno de uma educação para a diversidade.

Por esta razão, entre 2005 e 2010, os jovens de Campinho da Independência, jovens lideranças negras, tornaram-se referência de um forte debate crítico da educação homogeneizante do sistema oficial, em detrimento de uma educação para a diversidade que viesse a reconhecer os parâmetros da cultura negra e quilombola.

9 O Fórum é parte da Política Nacional de Desenvolvimento Sustentável dos Povos e Comunidades Tradicionais, criada pelo Decreto 6040, de 7 de fevereiro de 2007.

10 Lei 10 639/2003 que foi modificada pela Lei 11.645/2008, alterando a Lei no 9.394/96 - Lei de Diretrizes e Bases da Educação Nacional.

EntreRios - Revista do PPGANT -UFPI -Teresina • Vol. 3, n. 1 (2020) 
O primeiro passo do grupo com base nas leis vigentes para uma educação diferenciada, foi a de concorrer a um Ponto de Cultura ${ }^{11}$ que, instalada no interior do grupo, recebeu o nome de Ponto de Cultura Manoel Martins em homenagem a um ascendente do grupo. Contudo, o inesperado acontece: as atividades do Ponto de Cultura entram em conflito com os ensinamentos da escola local. ${ }^{12}$

A questão é que as atividades desenvolvidas com crianças e jovens da localidade no Ponto de Cultura apresenta um rendimento significativo em termos de saberes, conhecimento e aprendizagem. Por sua vez, essas mesmas crianças e jovens em idade escolar que cobre da educação infantil até o $5^{\circ}$ ano do Ensino Fundamental existente na comunidade, são negativamente avaliados pela escola e tidos como de baixo rendimento. A contradição expõe uma problemática que envolve os saberes oficiais que constituem o currículo escolar e que não reconhece os saberes produzidos pela memória histórica do grupo, passada de pais para filhos nas diversas gerações, através da oralidade. Segundo Gusmão e Souza (2012), a escola tradicional

não reconhece outros saberes produzidos no cotidiano de grupos sociais diversos, um cotidiano no qual ocorrem processos educativos de várias ordens envolvendo sujeitos sociais determinados numa trama que compreende processos diversos e múltiplos, dentro e fora da escola, e que conformam o entendimento do mundo e de suas práticas (GUSMÃO; SOUZA, 2012, p. 225).

Diante do problema, a reação inicial do grupo é a de estabelecer um diálogo centrado na troca de experiências que permita dialogar, o universo cultural do grupo com os saberes instituídos pelo currículo escolar. A intencionalidade e a ação se fazem, buscando levar para dentro da escola a experiência e as atividades vivenciadas no Ponto de Cultura. Contudo, a escola e seu formato tradicional acabam por impor limites à proposta feitas pelos jovens dirigentes da AMOQC. É nesse momento que, a proposta aberta visando "somar" experiências se radicaliza: em vez de uma educação de diálogo, os jovens dirigentes propõem que a escola se transforme em uma "escola quilombola", ou seja, da comunidade e para a comunidade negra. A proposta do grupo é a de pensar uma educação própria e diferenciada para as populações quilombolas, via uma pedagogia específica e local, sem negar a parceria com a escola, ou seja, através de uma pedagogia quilombola. O que seria uma pedagogia quilombola?

A proposta inicial da Associação de Moradores do Quilombo do Campinho - AMOQC era (e é) a de "agregar ao currículo escolar elementos do cotidiano da criança, uma contextualização no ensino, incluindo sua perspectiva de luta". (SANTANA et ali, 2016, p.146)

Aparentemente simples, contudo, a proposta desperta uma reação adversa entre os professores e com os gestores da Secretaria Municipal de Educação de Paraty. Apesar do revés e, pode-se dizer, por causa dele, é que os jovens da AMOQC, levarão a frente um projeto pedagógico-político próprio que, transcendendo os limites comunitários, os colocará como pioneiros num projeto de interesse das populações diferenciadas e, em específico, das comunidades quilombolas da região e do país, através de uma pedagogia quilombola, ela própria diversa e plural. Assim, o debate em torno dessa proposta amplia-se para além dos grupos quilombolas, estabelecendo diálogo com grupos indígenas, assentados, caiçaras, enfim, uma educação alternativa para os chamados povos tradicionais. Fato que vem sendo regulamentado por diferentes leis e decretos, porém, que encontra muita resistência da parte do sistema educacional e, mais particularmente, de órgãos gestores locais e de agentes no chão da escola.

11 Ponto de Cultura são iniciativas culturais desenvolvidas pela sociedade civil potencializadas pelo Governo Federal, através do programa Mais Cultura, e em conjunto com o Governo Estadual. Fonte: www.pontodecultura.rj.gov.br-acesso em 19/07/12

12 A partir daqui, reproduzo com pequenas mudanças, parte de textojá publicado (GUSMÃO, 2016a). 
O que os jovens quilombolas criticam são as atividades esporádicas ou pontuais ligadas a dias comemorativos presentes na atividade escolar, quando esta deveria ser pautada pela cultura negra cotidianamente vivida, a partir da realidade do grupo local e da historicidade do negro brasileiro de modo geral, pontuando fatos que se apresentam na vivencia do sujeito negro dentro e fora da comunidade. Portanto, uma pedagogia que extrapola os limites da escola e adentra um universo mais amplo da realidade negra, tornando-se significativa e importante meio de inclusão e reconhecimento, através da cultura e da educação. Trata-se de uma pedagogia que assume o sentido amplo de educação, não restrita à escola, mas com ela.

Mais que isso, na relação com outras comunidades tradicionais da região, por meio do Forúm de Comunidades Tradicionais, coloca-se em movimento o contato com outras experiências similares e, é estabelecida forte ligação de diferentes grupos tradicionais paratyenses a partir da experiência da AMOQC. Assim, constrói-se um forte diálogo local, regional e que se expande para com outros grupos de diferentes regiões brasileiras. O processo é significativo para repensar a instituição escola tal como se apresenta no sistema educacional, exigindo com isso, outros e novos princípios que redefinem o papel da escola, como escola voltada para a diversidade social e cultural dos diferentes grupos. Como afirmam Maroun e Arruti, citados por Santana et all (2016, p.146) o que está em pauta é a alteridade dos grupos diante da escola e, esta como extensão das comunidades em seu entorno, ou seja,

a "escola quilombola" reivindicada por Campinho se pauta fundamentalmente no princípio da alteridade, considerando a escola uma extensão da comunidade, isto é, um projeto político pedagógico comunitário (MAROUN; ARRUTI, 2011, p.9).

Um projeto político pedagógico desse nível coloca em tela a possibilidade de existência de uma educação quilombola, já explícita em diversos mecanismos jurídicos e políticos de uma educação para a diversidade. A questão que permanece é: quanto dela - educação quilombola e escola quilombola - de fato se efetiva? Qual o significado de uma educação para a diversidade que respeite a realidade pluriétnica da sociedade brasileira?

As perguntas são muitas, as respostas estão sendo construídas em diferentes regiões da nação brasileira por meio de experiências próprias no campo educacional e enfrentam não só o desafio de suas realidades diversas, mas o desafio de ter que dialogar com um sistema educacional homogêneo pensado para a sociedade como único e comum para todos. Esse um debate em andamento que envolve as possibilidades de contribuição de dois campos: a Antropologia e a Educação, e que expõe os limites de uma ordem inclusiva com políticas públicas que não alcançam ainda serem políticas sociais por excelência.

\section{Antropologia, Educação e Mediação: diálogos em construção}

No presente século, as lutas dos chamados grupos minoritários por reconhecimento e direitos evidenciam o não isolamento desses grupos, sejam eles quilombolas, indígenas, pescadores, assentados, ou outros, pois integram o tecido da nação brasileira. São grupos que almejam ser visibilizados em termos de suas identidades, culturas e direitos, de modo a garantir um lugar de fala. Sobretudo, reforçam os processos de emergência de lideranças que transcendem as lutas locais e assumem ações coletivas diante do Estado-nação. A consolidação de direitos, a viabilidade política e econômica, tanto dos grupos negros no meio rural e urbano, como dos demais grupos que compõem a população brasileira, constituem movimentos sociais dos quais emerge um campo político de atuação e defesa social e coletiva, "fazendo surgir novos atores políticos e novas formas de luta, entre as quais, a luta pela educação diferenciada, uma educação quilombola"(GUSMÃO, 2016a ,p.371). 
Gusmão (2016a) afirma que:

\begin{abstract}
A defesa de uma educação diferenciada pressupõe trocas efetivas entre o instituído pelo campo educacional e a necessidade de diálogos em pé de igualdade com outros saberes oriundos de tradição histórica diversa ou não reconhecida. Mais que isso, fica claro que as realidades quilombolas não pretendem se auto-isolar e fechar-se sobre si mesmas, posto que sempre, foram tais comunidades fruto das relações com a sociedade envolvente. $\mathrm{O}$ que pretendem é o reconhecimento das relações sociais que as caracterizam, sua historicidade e autonomia de modo a não serem negadas, invizibilizadas e excluídas no tecido social. Importa dizer e confirmar a diversidade de que são portadoras, de modo que ao legitimar direitos, legitimem e coloquem em pé de igualdade perante os homens e as leis, seus modos de vida, suas práticas culturais, aquilo que são como membros da sociedade inclusiva e, principalmente, como cidadãos (p.374/375).
\end{abstract}

Contudo, no Brasil até os dias atuais, ainda prevalece a falta de solução para a conquista de uma educação "de e para" os quilombos, razão pela qual, o caso de Campinho da Independência e sua proposta tornam-se referência para a construção de uma educação diferenciada, não apenas para eles, mas para todos os demais povos tradicionais, que, como eles, enfrentam desde sempre a negação de suas histórias nos currículos escolares.

Os relatos a respeito de duas comunidades - Brotas/SP e Campinho da Independência/RJ - através da história de suas lutas trazem à tona o que é educação e como ela se realiza nas relações entre sujeitos iguais e diferentes por meio de um contexto de encontros, desencontros, trocas e aprendizagens. A educação como um universo pautado pela mediação compreendida como espaço de relações, pressupõe o debate em torno da educação para diversidade e impõe a reflexão sobre cultura e cidadania, dois aspectos fundamentais na formação dos sujeitos sociais, de sua realidade social e política.

A educação considerada em uma concepção alargada, conforme defende Brandão (2004), coloca a si própria e a cultura como essenciais na compreensão da interioridade dos sujeitos e de como partilham relações de exterioridade com diferentes grupos, agências, dentre as quais a escola, o Estado, dentre outros. Assim, as ações de um grupo afetam outros grupos sociais e se fazem em meio de ações de afirmação da etnicidade e da identidade própria e singular, mas também, afetam e são afetados naquilo que possuem em comum e mais geral, de modo que uma luta particular dialogue com outras, e assim, pavimenta-se um caminho comum de luta. Uma luta maior. Nesse contexto, evidencia-se como as diferentes agências e agentes, medeiam, modelam e são modelados, tanto quanto modelam os próprios grupos ao trilhar com eles, os caminhos da cidadania, baseada no reconhecimento e nos direitos.

Portanto, a educação no sentido amplo, permite que alternativas se construam em meio de relações de poder adversas propiciadoras de identidades múltiplas, de conflitos e de ajustes em busca de uma meta maior, ou seja, os direitos próprios de cada grupo e o pleno reconhecimento como cidadão integrado à nação brasileira. Fato que exige e coloca em movimento uma rede de relações diversas, porém voltadas para a luta comum dos diferentes grupos. Assim, a interação entre sujeitos sociais que portam universos culturais, intelectuais e sociais distintos, exigem a compreensão do campo de poder em que atuam os grupos quilombolas e, também, os demais agentes no contexto da luta, de modo a compreender as realidades instituídas e dominantes, de modo a construir alternativas viáveis que assegurem direitos gerais e específicos. As ações entre sujeitos diversos opera, então, em meio a aprendizagens recíprocas de símbolos e significados, colocando a educação e a cultura como elementos chaves do processo de mediação no campo político e institucional. Fato que torna necessário um 
esforço analítico [..] premente no diálogo entre educação e antropologia, e exige não esgotar as possibilidades da educação no universo da escola, quer como ensino, quer como aprendizagem. Esse é um dos desafios postos pela relação antropologia e educação a ser considerada (GUSMÃO; SOUZA, 2018, p. 141).

A razão das demandas dos grupos quilombolas no contexto das políticas públicas brasileiras, como se viu nos exemplos citados, são ainda, projetos em construção ${ }^{13}$, dependentes dos avanços das próprias lutas, mas também do avanço do conhecimento nas áreas da antropologia e da educação, como espaços por excelência, de formação, atuação e contribuição às práticas dos agentes mediadores, seja o próprio antropólogo, o educador ou o professor no chão da escola, seja outros agentes e agências.

Portanto, o diálogo da antropologia com a educação (GUSMÃO, 2016b), envolve a relação de campos de conhecimentos diversos, com princípios também diversos e, fazem com que o universo da cultura e da educação, a partir das realidades empíricas que estudam e nas quais atuam, possam estabelecer caminhos de complementariedade entre saberes. Assim, constitui-se um universo em que a interdisciplinariedade atua de modo reflexivo entre os dois campos e, demarca responsavelmente, o compromisso para com as realidades sociais específicas e com sua humanidade.

Nesse contexto, ressalta-se o valor teórico das categorias com que opera a antropologia, como ciência e como prática, quais sejam, cultura e alteridade, fundamentais para indicar caminhos ou alternativas capazes de ir além das diferenças humanas e seu reconhecimento. Isso significa que a educação em sua forma mais ampla que a simples escolarização, porém contando com ela, deve considerar que a relação cultura e processos educativos implicam que,

o olhar antropológico é um olhar necessário para se compreender os fenômenos educacionais. Se compreendermos que a cultura é distributiva, como nos coloca Barth (2000), isso implica em dizer que os diversos sujeitos que vivenciam a experiência educacional possuem trajetórias distintas, e experiências culturais diferenciadas, o que lhes possibilita diversas formas de percepção, apropriação e construção do saber. Se de fato a cultura é lente através da qual nós vemos o mundo, como nos coloca Benedict (2004), também é a cultura a lente através da qual nós vemos a educação, logo, compreender a dinâmica desta lente mostra-se como uma tarefa fundamental [...]na medida em que se trata de um processo atrelado à constituição do próprio sujeito, vivenciada no processo de socialização, que é essencialmente aprendido (OLIVEIRA, 2012, p.125/126).

Assim, as categorias antropológicas de cultura e alteridade, envolvem a possibilidade da descoberta do "Outro", não apenas por sua diferença daquilo que sou, mas principalmente, pelo fato de tratarmos de contextos nacionais pluriétnicos, que para além do reconhecimento identitário e territorial, implica o reconhecimento do Outro como sujeito que possui um universo simbólico próprio, com práticas culturais específicas o que exige um processo profundo de reflexão e análise para que o conhecer e reconhecer esse Outro possa ser efetivo. Segundo Gusmão(2003),

A alteridade revela-se no fato de que o que eu sou e o outro é não se faz de modo linear e único, porém constitui um jogo de imagens múltiplo e diverso. Saber o que eu sou e o que o outro é depende de quem eu sou, do que acredito que sou, com quem vivo e por quê. Depende também das considerações que o outro tem sobre isso, a respeito de si mesmo, pois é nesse processo que cada um se faz pessoa e sujeito, membro de um grupo, de uma cultura e de uma sociedade. Depende também do lugar a partir do qual nós nos olhamos. Trata-se de processos decorrentes de processos culturais que nos formam e informam,

13 Segundo Arruti (2009) nas políticas existentes, quando se fala de uma educação para quilombolas, trata-se de atenção diferenciada para escolas em quilombos, mas não de ações para uma escola quilombola diferenciada. Segundo o autor, a educação de e para quilombolas, ainda está em busca de um caminho próprio. (p. 92)

EntreRios - Revista do PPGANT -UFPI -Teresina • Vol. 3, n. 1 (2020) 
deles resultando nossa compreensão do mundo e nossas práticas frente ao igual e ao diferente (p.87).

No dizer de Oliveira (2012), é assim que a antropologia se faz como ciência que se propõe a realizar uma mudança de perspectiva na forma de encarar o outro, o humano. (p. 126). Mudança que só é possível quando, para além da diversidade reconhecida pela Constituição de 1988 e pelos processos educativos formais, representado pela escola, caminhamos para além da multiculturalidade existente como fato, para adentrarmos as relações interculturais que caracterizam as relações sociais entre diferentes. Ou seja, compreendendo que

a cultura que nos move, envolve condições objetivas da vida em movimento, mas também, envolve os sentimentos, emoções e representações sobre o que é vivido. Nesse sentido, o que está em jogo não são as diferenças, mas a alteridade que constitui nosso mundo. Ou seja, as relações que nos constituem enquanto um nós coletivo, parte da realidade de sujeitos em relação, no interior de um contexto comum que partilham e, no qual se complementam e se confrontam negros, brancos e indivíduos de todas as cores (GUSMÃO, 2012, p. 97).

Nesse sentido, trata-se de relações sociais postas em um campo de tensão e de conflito permanente que exige serem compreendidas como um conjunto de relações que se movem por meio de "processos e estratégias políticas sempre inacabadas", ou seja, como processos de interculturalidade, sempre em movimento, posto que se trata de ação política intencional na gestão da diversidade social e cultural humana (GUSMÃO, 2017, s/p.). Assim, adentra-se um espaço mais profícuo das relações entre sujeitos sociais num campo de poder altamente estratificado, como o caso da sociedade brasileira. Um campo, no qual as diferenças, sejam apenas isso, e possibilitem aos grupos sociais em sua diversidade frente a outros grupos, a luta por um lugar em pé de igualdade e de direitos na realidade social. Nesse processo, a diversidade social e cultural dos grupos humanos, não se reduz a ser reconhecida, mas, se faz como caminho para a obtenção de direitos em pé de igualdade aos demais grupos da sociedade, como projeto e comoluta.

Portanto, assinala-se aqui, a importância da reflexão antropológica nos universos dos grupos minoritários que estuda e nos quais atua ${ }^{14}$, como no caso dos grupos quilombolas, indígenas e outros, de modo a tornar transparente as relações de poder, não só na vivência dos grupos, como, também, na formação e funcionamento dos estados nacionais na relação com os chamados diferentes, já que, desde sempre, os chamados diferentes, encontram-se presentes na realidade nacional.

\section{Para concluir}

A questão da diversidade e do contato cultural entre grupos é constitutivo da história da humanidade e se faz presente, de modo intenso, nas chamadas sociedades modernas. Disso resulta os impasses entre a ordem instituída, que, em seu movimento se defronta com formas diversas de organização da vida social. Não por acaso, portanto, a questão do desenvolvimento das sociedades nacionais, constitui um desafio e uma necessidade que articula princípios e práticas de intervenção e mediação junto a realidades social e culturalmente definidas por histórias próprias e singulares, como o caso dos grupos quilombolas na luta por seus territórios e por educação.

Como diz Ribeiro (2012), o campo do desenvolvimento supõe a presença de diferentes atores, cada um representando vários segmentos da população, além de "vários tipos de organi-

14 Considero que a ciência antropológica é uma ciência de ação ou em ação, ou seja, que intervém e medeia as relações nos e entre grupos que estuda, o que faz do antropólogo um mediador com responsabilidades teóricas e práticas presentes num campo de tensão, parte do campo político de relações entre sujeitos diversos (GUSMÃO, 2020b).

EntreRios - Revista do PPGANT -UFPI -Teresina • Vol. 3, n. 1 (2020) 
-zações governamentais, organizações não governamentais (ONGs), igrejas, sindicatos, agências multilaterais, entidades industriais e corporações financeiras" (p 199), todos movidos por interesses diversos, numa arena de luta e de confrontos.

Nesse embate que constitui o terreno político das relações sociais, os grupos de maior vulnerabilidade enfrentam relações de poder adversas, nas quais, se produz classificações e estereótipos "úteis para sujeitar pessoas por meio de simplificações que justificam a indiferença à heterogeneidade" (RIBEIRO, 2012, p.216).

Em meio a esse contexto, operam o fazer antropológico e os processos educativos que envolvem os diferentes grupos, bem como os grupos aqui considerados: o quilombo de Brotas acossado pelo desenvolvimento urbano e, o quilombo de Campinho da Independência que vê sua terra, repentinamente valorizada pela expansão de projetos de construção da Usina Nuclear de Angra dos Reis e da Rodovia Br-101, rodovia que cruza as terras do grupo, trazendo valorização, cobiça e conflito.

Nas trajetórias de lutas em que estão envolvidos os quilombolas de Brotas e de Campinho, pode-se perceber, de acordo com Ribeiro (2012), como se expressam os mecanismos discriminatórios que visam "reforçar diferenças previamente existentes em termos de classe, gênero, idade, raça e etnicidade", ao mesmo tempo que, as formas de participação em coletivos de luta, introduzem "novas lideranças, assim criando novas tensões dentro dos sistemas de poder e político preexistentes" (p. 226). Porém, como diz Ribeiro, "não há soluções fáceis para os conflitos de poder criados pelo campo do desenvolvimento" (p. 227).

O que se pode dizer a partir dos contextos descritos dessas duas realidades é que ambas são exemplares dos desafios do presente século, frente a existência social e política de grupos que se organizam e confrontam a sociedade inclusiva em seu modelo de expansão desenvolvimentista. Contudo, as trajetórias desses dois grupos, mostram

como depois da Constituinte em 1988, os acontecimentos se fazem múltiplos, complexos e colocam em questão as dimensões do que é ser cidadão brasileiro e como participar de uma sociedade de inclusão, em meio a diferenças e a desigualdades (GUSMÃO, 2020a, inédito).

Os cenários de ação e de luta, ao longo do tempo, se multiplicaram dando formas a experiências e aprendizagens em que trajetos e percursos se mostraram fundamentais para com as práticas de agentes e agências presentes na luta e, que trouxeram à baila os processos de mediação e seus efeitos. Como afirma Bezerra (2015), trata-se de "situações que envolvem etnicidade, formas de organização coletiva e implementação de políticas do Estado dirigidas a populações reconhecidas como culturalmente diversas" (p.10).

Por sua vez, na dinâmica das transformações, transforma-se também, o campo da antropologia e o papel dos antropólogos no interior dos grupos que estudam configurando, entre outras agências e agentes, o antropólogo como intérprete dessas realidades culturais e mediador das relações dos grupos com o Estado-nação, posto que serão os antropólogos com a ciência que praticam, sujeitos chamados pelas instituições oficiais para elaborar laudos territoriais que definem a comunidade negra como quilombola. Foram duas antropólogas responsáveis pelos Laudos Antropológicos de Brotas e de Campinho da Independência ${ }^{15}$. Ambas atuaram nesses grupos, em razão da legislação que define que os Laudos Técnicos de Identificação e Delimitação (RTID) com base no Art. 68, devem ser elaborados por antropólogos. A razão está em que, o trabalho antropológico implica o trabalho de campo, a realidade empírica e o diálogo com as lideranças, sendo o antropólogo visto como "perito" e agente mediador dos processos judiciais relativos aos direitos quilombolas. Mais uma vez, a antropologia se faz como

15 Refiro-me a antropóloga Patricia Scalli responsável pelo Laudo do Quilombo Brotas, em 2004, e a mim, Neusa M M de Gusmão como responsável pelo Laudo do Quilombo de Campinho da Independência, em 1997/98. 
ciência da ação e de mediação a operar a realidade da diversidade social e cultural de grupos minoritários frente ao Estado-nação.

No campo da educação, agentes do campo educacional, dentre estes, os professores que atuam no chão da escola, gestores e outros, ainda enfrentam contradições e conflitos em termos de conhecimento e ação/intervenção que envolve a questão da diversidade étnico-racial nas escolas.

Não obstante a existência de legislação voltada para tais realidades (LDB e PCNs), o que acontece via programas oficiais para tratar da educação junto aos quilombos, segundo Arruti (2009), é uma "atenção diferenciada para escolas situadas em área quilombola, mas não de ações para uma escola diferenciada para quilombolas" (p. 93). Ou seja, não resta dúvida quanto a política governamental que desde a Constituição em 1988, vem construindo propostas em torno do reconhecimento dos grupos quilombolas e suas demandas, mas, a efetivação dessas políticas esbarra em resistências e limites, de modo que ainda não alcança uma educação quilombola de e para os quilombos. Segundo Arruti (2009),

o debate de uma educação quilombola diferenciada - de e para os quilombolas - é parte, ainda, de um debate incipiente, porém, é um campo privilegiado de observação da emergência de demandas específicas, que fazem dos quilombolas hoje, "ativistas incômodos, localizados no mapa político nacional (p.104).

Como sujeitos atuantes no contexto político, os quilombolas de várias localidades brasileiras se unem e coordenam

ações no campo da educação [...] tomadas pelas próprias comunidades quilombolas, em parceria com organizações não-governamentais que se propõem aproximarem-se das secretarias de educação ou das próprias escolas e desenvolver cursos ou palestras sobre a valorização da história e cultura dos quilombos (GUSMÃO; SOUZA, 2012, p.241-242).

Estes, os casos dos quilombos de Brotas e de Campinho da Independência que, através da mediação de diferentes agentes e agências, se colocam em luta por uma educação diferenciada que constitui exemplos reflexivos e práticos, de "iniciativas ainda dispersas pelo campo da sociedade civil e mesmo internas ao Estado e ainda não sistematizadas na forma de uma política" (ARRUTI, 2009, p93).

A luta do povo negro por educação e superação do preconceito, mostra que a escola é ainda um valor para esses grupos, mas que, por sua natureza é ela ainda propagadora do preconceito e do racismo que precisam ser superados para dar lugar a políticas públicas e sociais que possam reconhecer a diversidade étnica-cultural dos diferentes grupos.

Assim, os chamados "quilombos contemporâneos", as comunidades negras de agora, encontram na educação, nas aprendizagens na escola e fora dela, o valor das leis que regulamentam reconhecimento e direitos. Abre-se um novo universo de luta e de ações que ensejam políticas públicas diversas e que colocam em movimento as mediações societárias e culturais entre eles e outros atores, na conquista da cidadania e de direitos, tendo em conta o pertencimento étnico, o direito à terra e outros direitos. Desta forma, o desenvolvimento da sociedade brasileira ao alcançar e se confrontar com grupos sociais diferenciados, modela um campo histórico de relações de contato, marcados por complementariedade, cooperação, mas, também, por negociações e conflitos.

Para (in)concluir o presente debate, cabe lembrar as afirmações de Ribeiro (2012), de que o desenvolvimento não é inocente e os conflitos não são de simples solução. Porém, o conflito é a alternativa a tornar a heterogeneidade um valor central na promoção do convívio, criatividade e capacidade de inovação humana. Este o desafio do século XXI para a construção de uma sociedade mais justa e equânime. 


\section{Referências Bibliográficas}

ARRUTI, J.M. “Políticas públicas para quilombos: terra, saúde e educação”. In: PAULA, M.; HERINGER, R. (orgs.) Caminhos Convergentes. Estado e sociedade na superação das desigualdades raciais no Brasil. Rio de Janeiro: Fundação Heinrich Böl Stiftung/ActionAid, 2009, pp. 75-110. Disponível em: http://geraaufms.blogspot.com/2011/06/jose-mauricio-arruti-politicaspublicas.html Acesso em: 13/11/2018.

BEZERRA, Marcos Otávio. Prefácio. In: VALLE, Carlos G. Etnicidade e Mediação. São Paulo: Annablume Editora, 2015, pp. 7-12

BRANDÃO, Carlos R. O queéEducação. São Paulo: Brasiliense, 2004.

GUSMÃO, Neusa M. M. Terra de Pretos, Terra de Mulheres, Terra, Mulher e Raça num Bairro Rural Negro. Brasília: Ministério da Cultura, Fundação Cultural Palmares, 1995, $1^{\text {a }}$ edição.

. "Os desafios da diversidade na escola”. In: GUSMÃO, Neusa M. M. (Org.). Diversidade, cultura e educação: olhares cruzados. São Paulo: Biruta,2003, pp. 83-105.

. "Africanidades e Brasilidades: desafios da formação docente". REALIS - Revista de Estudos AntiUtilitaristas e Pós-Coloniais, 2 (1), jan-jun 2012: 93-108. Disponível em: https://periodicos.ufpe.br/revistas/realis/issue/view/1166. Acesso em 12/03/2020.

. "Quilombo Campinho da Independência: direito insurgente, luta quilombola e educação". In: ROJAS, A.; PIRES, Antonio Liberac C. S.; GOMES, Flávio dos Santos. Territórios de Gente Negra. Processos, transformações, adaptações sobre Colômbia e Brasil. Coleção Uniafro, v. 17, Cruz das Almas: Editora UFRB; Belo Horizonte: Editora Fino Trato, 2016a, pp 359-378.

. "Antropologia, Cultura e Educação na Formação de Professores". Revista Anthropológicas, A n o $20,27(1), \quad 2016 \mathrm{~b}: 45-71$. D i s p o n íve 1 e m : https://periodicos.ufpe.br/revistas/revistaanthropologicas/issue/view/1405 Acesso em: $10 / 02 / 2020$.

- Prefácio. In: NASCIMENTO, Raimundo N. Ferreira. Antropologia, interculturalidade e educação escolar em Roraima. Curitiba: Appris Editora, 2017.

“Quilombos e quilombolas: dizeres acadêmicos, jurídicos e políticos na dança das Categorias". Texto inédito, No prelo. 2020a.

. "Antropologia, Educação e Ética: desafios no e do campo científico". Texto inédito. No prelo. 2020 b.

GUSMÃO, Neusa M.M.; SOUZA, Márcia Lúcia A. “Educação Quilombola entre saberes elutas”. In: DAUSTER, Tania; TOSTA, Sandra P.; ROCHA, Gilmar (orgs.) Etnografia e educação. Rio de Janeiro: Lamparina, 2012, pp. 222-245.

"Etnografias na/e educação: um olhar sobre quilombolas no Brasil e africanos em Portugal. Dossiê Estudos Etnográficos em Educação". Revista Contemporânea de Educação, 13 (26), jan/abr 2018: 125 - 145. Disponível em: https://revistas.ufrj.br/index.php/rce/issue/view/969. Acesso em 20/12/2019. 
OLIVEIRA, Amurabi. “Antropologia e Antropólogos, Educação e Educadores: o lugar do ensino de Antropologia na formação docente". PerCursos, 13 (01), jan - jun 2012: 120 - 132. Disponível em: http://www.revistas.udesc.br/index.php/percursos/issue/view/255 Acesso em: 25/04/ 2020

RIBEIRO, Gustavo Lins. “Poder, redes e ideologia no campo do desenvolvimento". In: ZHOURY, Andréa. Desenvolvimento, reconhecimento de direitos e conflitos territoriais. Brasilia-DF; ABA, 2012, pp. $196-229$.

SANTANA, José Valdir J; EUGÊNIO, Benedito G; OLIVEIRA, NAKSON W.S.; PEREIRA, Claudia de J. "A Educação Escolar Quilombola na ANPED: análise da produção do GT. 21 Educação e Relações Étnico-Raciais”. ACENO, 3(6), Ago - Dez 2016: 137-158. Disponível em: http://periodicoscientificos.ufmt.br/ojs/index.php/aceno/article/view/4333/pdf Acesso em: 02/05/2020

SOUZA, Marcia Lúcia Anacleto. Educação e Identidade no Quilombo Brotas. Dissertação de Mestrado. Programa de Pós-Graduação em Educação, UNICAMP, 2009.

VALLE, Carlos G. Etnicidade e Mediação. São Paulo: Annablume Editora, 2015. 